Research Article

\title{
Governance of Relationship Risks in Megaprojects: A Social Network Analysis
}

\author{
Linlin Xie $\mathbb{D}^{1},{ }^{1}$ Ting Han, ${ }^{1}$ and Martin Skitmore ${ }^{2}$ \\ ${ }^{1}$ South China University of Technology, Guangzhou, China \\ ${ }^{2}$ Queensland University of Technology, Brisbane, Australia \\ Correspondence should be addressed to Linlin Xie; 1lxie@scut.edu.cn
}

Received 18 May 2019; Revised 12 August 2019; Accepted 9 September 2019; Published 25 September 2019

Academic Editor: Emilio García-Taengua

Copyright (c) 2019 Linlin Xie et al. This is an open access article distributed under the Creative Commons Attribution License, which permits unrestricted use, distribution, and reproduction in any medium, provided the original work is properly cited.

Megaprojects usually involve an alarmingly large number of stakeholders that form a complicated social network and lead to significant relationship risks to client/owners. Therefore, it is necessary to carry out megaproject risk management from a sociological point of view. Based on a case study of the Zhuhai Port, which connects Hong Kong, Zhuhai, and Macao, this paper analyzes the relationship risk between stakeholders and corresponding risk management strategies using social network analysis (SNA). The findings show that stakeholders with a lower density and higher centrality in the network have comparatively a lower relationship risk. Different stakeholders should choose appropriate partners to improve their centrality, reduce the network density to increase their ability to access resources, and enhance their influence and independence in the network. For megaproject client/owners, identifying and monitoring key stakeholders is the key to effective relationship risk governance. The findings provide a number of practical implications for relationship risk management and further demonstrate the importance of stakeholder teamwork, particularly for megaprojects.

\section{Introduction}

Megaprojects are large-scale, complex infrastructure projects [1] that are defined broadly as projects that transform landscapes rapidly, intentionally, and profoundly in a very visible way and require the coordinated application of capital and state power [2]. Their fundamental purposes are to ensure national security, increase economic development, improve people's lives, and promote social progress [3]. They are characterized by complexity, uncertainty, ambiguity, dynamic interfaces, and significant political or external influences $[4,5]$. The delivery of megaprojects involves various stakeholders and usually requires interregional and multiagent cooperation. These stakeholders play different roles and undertake different responsibilities and obligations, forming a complex social network. This characteristic reflects the social attributes of megaprojects, which is one of the important reasons for their complexity [6].

The social attributes of megaprojects, as a result, lead to significant relationship risks, which is the product of dynamic interaction between stakeholders [7]. The project stakeholders' position in the project social network and their interaction have an important influence on the realization of the expected yields; this "influence" is defined as the relationship risk [7]. Previous research on project governance mainly focuses on control and trust as the main mechanism of governance [8, 9]; in fact, the relationship between project subjects is a breakthrough. The relationship between stakeholders is very important for project governance, and it is necessary for the risk management of megaprojects to be carried out from a sociological perspective. However, traditional methods of risk management pay more attention to technological issues, ignoring the dynamic interactions between stakeholders, paying more attention to project "attribute" risks, and rarely involving the study of stakeholder relationship risks [7].

Relational governance is critical to project success [10], and stakeholder-oriented project governance is the success factor of the project, so great attention should be paid to stakeholders in the project governance [11], especially the role of the government because the government is positively correlated with the success of the project [8]. Social network 
analysis (SNA) is often used to test human relationships [12]. It can quantify the abstract relationship between stakeholders [13], reveal the interactions between actors [14], identify relationship risks in projects [15], explore the most important social risks of high-density urban construction projects by using the method of improving social network [16], and facilitate the adoption of risk management measures based on the network characteristics [7]. As a result, there is an increasing amount of research into SNA applications in construction project management. However, SNA has been barely applied to risk management to date, especially the management of relationship risks between the stakeholders of major projects.

Taking the Zhuhai Port project of the Hong KongZhuhai-Macao Bridge as a case, this study aims to address the relationship risks in megaprojects using various indexes of the SNA approach. The specific objectives are (1) to analyze the relational structure and mutual influences among various stakeholders involved, (2) to identify potential risks and feasible solutions, and (3) to develop corresponding risk management strategies from different perspectives. The results identify the practical implications of megaproject risk management and enrich the understanding of their relationships governed.

The remainder of this paper is structured as follows: Section 2 presents a comprehensive literature review, followed by a detailed elaboration of the research methods in Section 3, including data collection, modeling, and selecting relevant indicators. Section 4 analyzes the results of using the social network indicators. Section 5 analyzes potential risks and discusses effective strategies, and Section 6 provides a summary of the study and proposes corresponding suggestions from different perspectives.

\section{Literature Review of SNA}

SNA is a method used by sociologists to analyze the structural characteristics of the relationships between social actors [17]. The network consists of nodes and connecting lines. The nodes can be individuals, organizations, or other social entities, and the lines between nodes refer to the interactions between individuals sharing experiences, resources, or information. The project, which is a network formed by various stakeholders and their interactions, has the characteristics of a social network [18]. The success of the project stems not only from the optimum plan, efficient allocation of resources, and utilization of control functions but also from a high-performance team, where the project participants communicate, exchange information, cooperate, etc. to complete the whole project efficiently and effectively [19]. Moreover, megaproject social networks are highly complex because of the large number of participants involved and great impact on society.

The SNA method of using graph theory and the matrix format to depict and assess the characteristics of the interrelations between actors [20] and to examine how relationship structures influence behaviors, SNA metrics, and concepts applied in complex-project-management research can be classified into four categories, depending on the role of each in the network: formation mechanisms of a network, centrality, connectedness of a network, and network topology [21]. The method is concerned with the "structure and patterning" of these relationships over time and seeks to identify both their causes and effects [22]. As Winter et al. [23] showed, SNA is an important method for analyzing the structure and relationship between stakeholders in a relational network. Badi and Diamantidou [24] using SNA identified, quantified, analyzed, and visualized the relationship of main stakeholder groups [24]. Cai et al. [25] revealed the relationship between the social structure and employees by using SNA [25]. Furthermore, it can help identify potential project threats [26], provide an effective means of coping with possible risks in complex projects, and improve project performance through such flexible management aspects as trust and cooperation [27].

SNA was first introduced for construction project management in as recently as the 1990s. It was mainly used by Loosemore [28], Hossain [29], and Ding and Liu [30] to study the individual relationships at the project level and by Soda et al. [31], Pryke [32], and Yongkui et al. [33] to study the relationship governance between construction enterprises at the industry level. Taylor et al. [34] combined BIM with social network theory in the belief that, in addition to focusing on technical interflow between different professionals, the application of BIM in the field of engineering construction should pay attention to information exchange between the organizations in the network. Nelon et al. [35] used a social network analysis (SNA) to assess the quality and strength of relationships between project participants. Badi et al. [36] showed the organizational communication relationship between project participants through the measurement index of SNA, while Liu [37] combined SNA with kinetic theory for the dynamic analysis of network governance.

Of the very limited studies applying SNA to risk management, Loosemore [28] used SNA to complement quantitative techniques and explore construction crisis management. This involved using tabu fractional data to measure the degree of communication and contact between members of the entire network and centrality to measure the degree of mastery of information to help in understanding and providing explanations of people's changing social roles, positions, and behaviors during the course of a construction project. Content analysis was also used to determine the reliability of the results concerning the SNA-based analysis of participants' behavior. In another study, Loosemore [38] used SNA to analyze project risks caused by the misalignment of power and responsibilities of construction project participants. Aaltonen et al. [39] analyzed the relationship between the actors in the network using SNA, pointing out that the organization with high centrality in the network is at the core of the network, can control the flow of project information, and can affect the behavior of other actors. Yuan [40] used SNA to analyze the risk management organization of subway construction projects and analyzed the network density and concentration of the social network structure of subway construction projects from two aspects: the 
whole network and the individual network. More recently, Lingard et al. [41] used SNA to study 13 cases from 10 construction projects in Australia/New Zealand to (1) compare the characteristics of the contractors' social networks in terms of network density (the ratio of actual links between participants in the project network relative to the maximum number of links possible) and (2) measure the degree centrality (the extent to which the contractor communicated with other parties), pointing out that the contractor's involvement in the planning and design phases of construction can reduce its own risk.

Therefore, social network analysis (SNA) is applicable to evaluating governance networks formed by stakeholders and their relationships [42]. The SNA node's position in the network can be used to judge its power and influence and limitation of stakeholders, and the SNA network density index studies the relationship between stakeholders and identifies potential risks and feasible solutions by means of SNA indicators. In general, the social network analysis method is suitable for the study of relationship risks in project management.

\section{Research Methods}

Case studies provide an effective tool for analyzing complex and specific problems in real life. As risk management based on SNA is not mature at present, one such case study was conducted to apply SNA for in-depth examination of the interactions between stakeholders in megaprojects and the resulting relationship risks. The case selection was not random but based on theoretical/selective sampling [43], with the Zhuhai Port project chosen because of numerous stakeholders involved with complex interactions bringing great challenges to the coordination and management of the project.

3.1. Variable Measurement. The network is a collection of nodes and their relationships, and the social network is a collection of social actors as nodes and their relationships. The method of social network analysis mainly uses graph theory and matrix to construct the mathematical model of the social network. The value of the relational data between nodes can be binomial, in which " 0 " represents no relationship between two nodes and "1" represents the relationship between two nodes [44]. SNA places even greater emphasis on the network ties than the nodes' characteristics [45]; it can also be weighted value, which represents the strength of the relationship between two nodes. In addition, the relationships can be divided into directed and undirected according to whether the directionality of the relationship between nodes is taken into account. The social responsibility network of megaprojects is a set of stakeholders and their relationships. In this paper, each node represents the project stakeholders separately, and the relationship between the nodes is measured by the degree of mutual influence. Because the degree of influence between the stakeholders is unequal and the degree of influence is different, this study adopts "directed-weighted links" to express the "relationship."
3.1.1. Density. This value is used to measure the tightness of nodes. It represents the proportion of relationships that actually exist in the network to the largest number of possible relationships. For example, the density of the social network is 1, which indicates that there are connections between any two nodes in the network; if the density is 0 , it means that any node exists independently. The greater the density of the network, the more the links and the more the contacts among stakeholders, which shows that the relevant entities are more constrained by other entities. But for the whole social network, it is conducive to stabilizing the regulatory relationship between stakeholders.

In this paper, we use the experience of predecessors to calculate the network density by using the multidegree method. The formula for density calculation is as follows:

$$
\text { density }=\frac{L}{N}(N-1) \text {, }
$$

where $N$ and $L$ refer, respectively, to the number of stakeholders and links.

3.1.2. Centrality. Centrality is an attribute used to measure the degree of individual relevance. The position of a node in the network can be used to judge the degree of its power and the influence and limitation of the stakeholders. It includes the degree centrality, betweenness centrality, and closeness centrality.

Degree centrality refers to "the number of direct contacts with a certain node," which reflects whether a relevant party has close trading links in the network. Betweenness centrality is defined as that "losing this node, the connection between nodes will be lost," which reflects the extent to which an entity can act as the intermediary of other entities to measure the degree of control of resource information by a relevant party. Closeness centrality is the "distance level between nodes," which reflects the impact of one entity on another entity, and is used to express the ability of information and resource sharing among groups. These three attributes can be calculated and analyzed by means of quantification. The formulas for calculating the three centralities are as follows:

$$
\begin{aligned}
\text { degree centrality : } C_{D}\left(n_{i}\right) & =\frac{d_{I}\left(n_{i}\right)+d_{O}\left(n_{i}\right)}{2(N-1)}, \\
\text { betweenness centrality : } C_{B}\left(n_{i}\right) & =\frac{\sum^{g_{j k}\left(n_{i}\right) / g_{j k}}}{(N-1)(N-2)},
\end{aligned}
$$

where $g_{j k}$ indicates the number of shortcuts between the point $j$ and the point $k$ and $g_{j k}\left(n_{i}\right)$ refers to the number of shortcuts between two correlators including the correlator $n_{i}$.

$$
\text { Closeness centrality: } C_{C}\left(n_{i}\right)=\frac{N-1}{\sum_{j=1}^{N} d\left(n_{i}, n_{j}\right)},
$$

where $d\left(n_{i}, n_{j}\right)$ refers to the geodesic distance between the node $n_{i}$ and the node $n_{j}$. 
3.2. Case Information. Zhuhai Port is a national key project linking Hong Kong, Zhuhai, and Macau. It is also a megaproject under the coexistence of two different political systems and has a profound effect on the economic and social integration of the three areas.

With an estimated cost of approximately CNY 5 billion and total construction area of about $480,000 \mathrm{~m}^{2}$ (including ground and underground construction areas), the project is divided into four construction sections. The project started on December 31, 2013, and was scheduled to be completed by the end of December 2016. However, it was postponed for a year, and the official completion date is March 30, 2018. The stakeholders involved in the project include departments and units directly involved in the construction of the project, customs, frontier inspection, national inspection, and Quarantine Bureau.

The agent construction system is being used, involving the three local governments, construction agent units, supervisors, designers, general contractors, and subcontractors. As the main investors, the Zhuhai municipal government and the Guangdong provincial government are essentially the owners. The Hong Kong-Zhuhai-Macao Bridge Zhuhai Port Leadership Coordination Management Office (Bridge Office) plays a supervisory and coordination role, and the GREE Hong Kong-Zhuhai-Macau Bridge Project Management Company has been entrusted by the government to act as an agent for the construction and operation. The stakeholders at various stages of the project are summarized in Table 1.

From the above, we can find that there are many different companies for the same kind of stakeholders. In subsequent data collection and network model construction, companies belonging to the same kind of stakeholders are considered a kind of stakeholder group.

3.3. Data Collection. The network nodes (stakeholders in the network) were first identified through interviews by snowball sampling, in which we started with small network actors who were asked to nominate other participants with a specific relationship. Similarly, the participants nominated were asked to nominate other actors until no new person was mentioned [46]. The final choice of the stakeholders included Guangdong and Zhuhai government officials, agent construction units, contractors, suppliers, supervisors, designers, scientific research (technical department), public facility (relevant) management departments, financial institutions, consultant, and operation department.

A questionnaire survey was then used to collect data for an in-depth analysis of the interactions between stakeholders. This involved respondents scoring the relationship between the stakeholders from a directed weighted graph from 0 (no impact) to 3 (large impact). 130 questionnaires were dispatched, and 104 responses were received, of which 6 were deemed invalid.

According to Table 1, it can be seen that the same stakeholder group in the project may be involved in different corporates (e.g., four contractors), and this study regards them as a whole stakeholder group (e.g., the four contractors are represented by the node "contractor"). Considering that data of a node from different organizations may lead to data deviation because of interorganizational differences, the cognitive differences of different corporates with the same role are analyzed first after data recovery. After confirming that there is no significant interorganizational difference, the data are merged into the same group.

Furthermore, the respondents' backgrounds were diverse, comprising governments (9), construction agent units (16), contractors (28), suppliers (7), supervisors (13), designers (14), and others (11). Based on the sample size of each group, the average value of each group represents the final marking matrix of the group, where $X_{i}$ represents the final marking matrix of the stakeholder group $i$. Each matrix $X_{i}$ was then modified by an adjustment coefficient $\beta_{i}$ before adding all the correction matrices to obtain the final marking matrix $X$. The specific calculation formulas are as follows:

$$
\begin{aligned}
& \beta_{i}=\frac{1}{N} \times \frac{n}{n_{i}}, \\
& \mathrm{X}=\sum_{i=1}^{N} \beta_{i} \cdot X_{i},
\end{aligned}
$$

where $N$ represents the number of stakeholder groups (7 in this study), $n$ represents the total number of samples, that is, the valid number of questionnaires (98 in this study), and $n_{i}$ represents the sample number of the stakeholder group $i$.

\section{Results and Analysis}

4.1. Establishment of the SNA Model. The adjacency matrix of stakeholders of the Zhuhai Port project was established based on statistical analysis of the questionnaire survey data (Table 2).

Based on the matrix diagram, the social network diagram of the project is obtained with the NetDraw software, as shown in Figure 1. The network is a directed weighted graph, where each node in the graph represents the stakeholders involved in the project and the directed arrow is weighted to indicate the direction and degree of connection with each other.

Indices of network density and centrality were adopted to quantify the relationships between stakeholders.

4.2. Analysis Based on SNA. Using the UCINET software, the values of each node's related parameters are shown in Table 3, with an overall network density $\Delta$ of 0.8182 and a standard deviation of 1.0373 .

4.2.1. Density Analysis. Density expresses the tightness of the links between various stakeholders, defined as the sum of the actual ties divided by the number of possible ties [30]. The greater the overall network density, the stronger the connections and the more the constraints among the agents in the network. The overall density of 0.8182 means the actual relationship in the network accounts for $81.82 \%$ of all possible relationships and shows that the overall network density is high, and the connection between stakeholders in 
TABle 1: Project stakeholders.

\begin{tabular}{|c|c|c|}
\hline Stakeholders & Name & Main responsibilities \\
\hline Superior authority & Bridge Office & $\begin{array}{l}\text { Early stage: project construction and coordination } \\
\text { Later stage: coordination management }\end{array}$ \\
\hline Construction agent unit & $\begin{array}{l}\text { GREE Hong Kong-Zhuhai-Macau Bridge Project } \\
\text { Management Company }\end{array}$ & Project construction and operation management \\
\hline \multirow{2}{*}{ Designer } & $\begin{array}{l}\text { East China Architectural Design \& Research } \\
\text { Institute }\end{array}$ & Package design \\
\hline & $\begin{array}{c}\text { Shanghai Urban Construction Design \& Research } \\
\text { Institute }\end{array}$ & Municipal design (plaza, garden) \\
\hline \multirow{4}{*}{ Contractor } & $\begin{array}{l}\text { China Construction Third Engineering Bureau } \\
\text { Co., Ltd. }\end{array}$ & General contract for construction of bid section I \\
\hline & $\begin{array}{l}\text { Guangxi Construction Engineering Group Fifth } \\
\text { Construction Engineering Co., Ltd. }\end{array}$ & Construction contract of bid section II \\
\hline & Shanghai Urban Construction & $\begin{array}{c}\text { Construction contract of bid section, connecting } \\
\text { line approach span }\end{array}$ \\
\hline & $\begin{array}{l}\text { Guangdong Yao Nan Construction Engineering } \\
\text { Co., Ltd. }\end{array}$ & Construction contract of bid section \\
\hline Supervisor & $\begin{array}{l}\text { Guangdong Chinese Laborers Engineering } \\
\text { Construction Supervision Co., Ltd. } \\
\text { Zhuhai urban construction supervision }\end{array}$ & $\begin{array}{l}\text { Supervision of section I, II, and IV tenders } \\
\text { Supervision of section tenders }\end{array}$ \\
\hline Supplier & Concrete and steel structure suppliers & $\begin{array}{l}\text { Providing engineering materials and equipment } \\
\text { for construction }\end{array}$ \\
\hline \multirow{4}{*}{$\begin{array}{l}\text { Relevant management } \\
\text { department }\end{array}$} & Housing and Urban Planning Bureau & Planning and power coordination \\
\hline & $\begin{array}{l}\text { Zhuhai Construction Engineering Quality } \\
\text { Supervision and Inspection Station }\end{array}$ & Quality supervision \\
\hline & $\begin{array}{c}\text { Zhuhai Construction Engineering Safety } \\
\text { Supervision Station }\end{array}$ & Construction safety supervision \\
\hline & Transport sector & Traffic coordination for construction land \\
\hline Technical department & $\begin{array}{c}\text { Guangdong Oriental Thinking Science and } \\
\text { Technology Limited Company, Guangdong } \\
\text { Tongwang Technology Co., Ltd. }\end{array}$ & $\begin{array}{l}\text { Development of integrated information system for } \\
\text { the main project }\end{array}$ \\
\hline Others & $\begin{array}{l}\text { Local people, users, financial institutions, } \\
\text { operation department }\end{array}$ & $\begin{array}{l}\text { Be affected by the project and participation in the } \\
\text { project to a certain extent }\end{array}$ \\
\hline
\end{tabular}

the network is close. However, although the members of such a network are more likely to achieve consensus expectations and goals through negotiation and communication, the constraints are high.

Ego density is the ratio of the number of actual relationships to all possible relationships between a point and the other points. It measures tightness of the link between the node and other nodes-the greater the value, the greater the influence of other stakeholders and the greater the degree of being constrained by others. The individual network density results indicate the individual network density of the government and construction agent unit to be the lowest, which means they have greater autonomy and fewer constraints of other stakeholders in the network. In contrast, scientific research institutions, financial institutions, and public facility management departments are largely restricted by other stakeholders, with higher individual network risks.

\subsubsection{Centrality Analysis}

(1) Degree Centrality. The degree centrality measure is the ability of a node to contact directly the other nodes. A node's in-degree and out-degree centralities represent the degree to which the stakeholder is a receiver or sender, respectively, of the information from or to its neighbor nodes [28]. "Indegree" means the degree of influence by others, and "outdegree" means the ability to control information and influence others. It is worth noting that degree centrality only considers the direct relationship of the subject and reflects the local situation of the network. The out-degree centrality of the government is the largest (70\%), followed by the agent construction unit $(66.67 \%)$. The supplier has the highest indegree centrality (43.33\%), followed by the contractor and the designer (40\%), which means that these five have close ties with other stakeholders in the network, with greater influence. Among them, the government and agent construction unit are the main influencers, while the supplier and designer belong to the main agent influenced by others. Contractors are in a relatively balanced situation in the network (in- and out-degree are basically the same).

(2) Closeness Centrality and Betweenness Centrality. The closeness centrality is calculated by distance. The greater the value, the closer to others and the stronger the influence. "Outcloseness centrality" refers to the distance from a point to the other points, and the greater the value, the more likely the actor is to control others. "In-closeness centrality" refers to the 


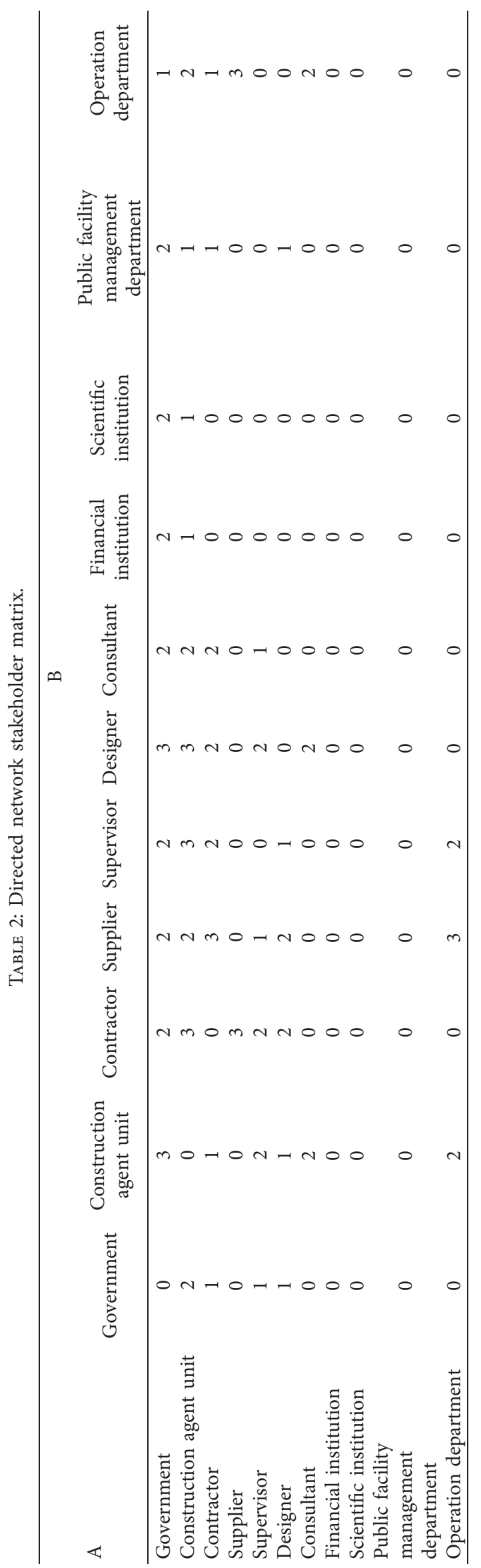




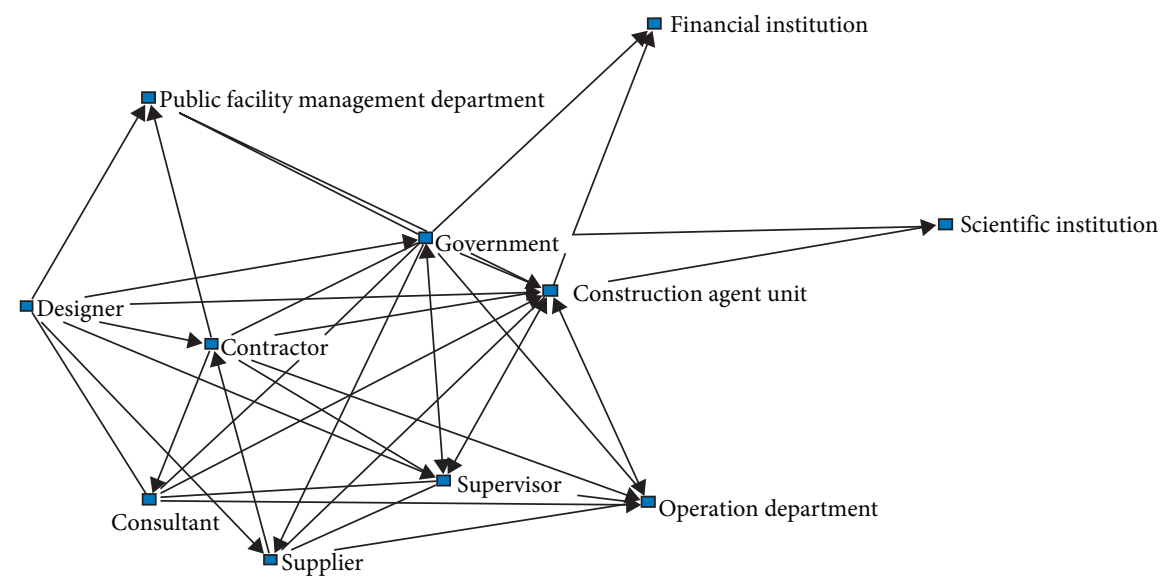

FIgURE 1: Social network of stakeholders.

TABLe 3: Centrality and individual network density of stakeholders.

\begin{tabular}{lcccccc}
\hline Stakeholders & \multicolumn{2}{c}{$\begin{array}{c}\text { Degree centrality } \\
\text { Out- } \\
\text { degree }\end{array}$} & $\begin{array}{c}\text { In- } \\
\text { degree }\end{array}$ & $\begin{array}{c}\text { Betweenness } \\
\text { centrality }\end{array}$ & $\begin{array}{c}\text { Closeness centrality } \\
\text { Out- } \\
\text { closeness }\end{array}$ & $\begin{array}{c}\text { In- } \\
\text { closeness }\end{array}$ \\
\hline Government & 70.000 & 16.667 & 19.815 & 100.000 & 23.256 & 37.38 \\
Construction agent unit & 66.667 & 36.667 & 19.815 & 100.000 & 24.390 & 35.56 \\
Contractor & 43.333 & 40.000 & 3.148 & 83.333 & 23.810 & 55.36 \\
Supplier & 20.000 & 43.333 & 0.370 & 50.000 & 24.390 & 83.33 \\
Supervisor & 30.000 & 33.333 & 0.741 & 71.429 & 23.810 & 69.05 \\
Designer & 26.667 & 40.000 & 2.037 & 71.429 & 23.810 & 59.52 \\
Consultant & 20.000 & 23.333 & 0.370 & 58.824 & 23.256 & 83.33 \\
Financial institution & 0.000 & 10.000 & 0.000 & 9.091 & 27.027 & 100.00 \\
Scientific institution & 0.000 & 10.000 & 0.000 & 9.091 & 27.027 & 100.00 \\
Public facility management & 0.000 & 16.667 & 0.000 & 9.091 & 29.412 & 100.00 \\
department & 23.333 & 30.000 & 0.370 & 58.824 & 23.810 & 73.33 \\
Operation department & & & &
\end{tabular}

distance from other points to a point, and the larger the value, the greater the degree of constraint of the stakeholder.

Betweenness centrality measures the ability of the agent as a medium, that is, he is in an important position between the other two people. If he refuses to be a medium, the mutual influence between the two people will not be transmitted. The range of the indicator is $0-1$ (the percentage system is adopted in this paper). The greater the value, the greater the influence of the agent on the relationship between others and the stronger the influence and control ability on others. 0 means that the existence of this agent has no effect on the relationship between any other two actors, and 1 means that the point can control other actors $100 \%$.

The government and the construction agent unit have the largest betweenness degree (19.815\%), indicating that these stakeholders are at the core position in the social structure, and their ability to control resource information is strong. The government and the construction agent unit also have the largest out-closeness centrality (100\%), showing that they have greater influence on others in the process of project governance. The public facility management department has the highest in-closeness centrality (29.412\%), indicating its ability to acquire resources is weak and is easily influenced by others.
Taken all together, the government and construction agent unit have a large out-degree centrality, higher betweenness centrality, and higher out-closeness centrality. This implies that the government and the construction agent occupy the core position in the project social relation network, have a greater ability to control resources and information with higher power and influence, and thus have obvious advantages and are key stakeholders. The financial institution, scientific institution, and public facility management department all have similar network characteristics of lower degree (both out- and indegree) and betweenness centrality and lower out-closeness centrality. Overall, these three stakeholders occupy the edge of the network, with their influence and access to information being weak. In fact, they are also not the main participants in construction. The rest of the stakeholders all have a relatively higher degree centrality but a relatively lower betweenness and closeness centrality. Their ability to obtain and control resources is therefore relatively balanced and mainly restricted by the government and construction agent unit.

4.2.3. Relationship Risk Analysis. From the perspective of a social network, a network structure is formed by the interaction between the stakeholders in the project [47]. 
Stakeholders in different locations in the relational network have different risks [28]. Through the above analysis, the relationship risk in the project is mainly from two aspects: one is influence (power) and the other is restriction. The stakeholders with greater power are more likely to have access to the information and resources they need [48]. Moreover, they even grasp the key resources and information that are necessary for other stakeholders throughout the project. In this case, the unstable sources of resources and information place stakeholders with weaker power in a relatively disadvantageous position [49]. Meanwhile, the degree of closeness to each other determines to some extent the smoothness of information exchange within the organization [7]. Usually, the more frequent the communication, the more transparent the information, which helps to reduce project risks for project managers. However, for individuals that lack the necessary resources and have relative disadvantages (that is, less power), increased transparency means less negotiation advantage, and more attention will be paid to their behavior. In such circumstances, according to the resource dependence theory [50], the project stakeholders will be greatly restricted.

The degree of power is measured by centrality, and the degree of restriction is measured by density [51, 52]. The greater the ego centrality, the stronger the influence, which means the autonomy of their behavior is higher. Similarly, the lower the degree of ego centrality, the smaller the influence, which means a higher dependence on others in the project. The greater the density of individuals, the closer they interact with other stakeholders and the more the restrictions they are subject to. Conversely, the smaller the individual density, the higher the autonomy of behavior. Therefore, the next section mainly measures risk from the two dimensions: centrality and density, and proposes corresponding response strategies.

\section{Risk Corresponding Strategies}

5.1. Types of Strategies. As shown in the above analysis, different stakeholders have different density and centrality, namely, different influences and restrictions. At the individual level, the greater the ego density, the greater the connection with others, but with greater constraints placed by others. Centrality mainly reflects the individual's influence in the network. Of the three kinds of centrality, degree centrality cannot exactly reflect the position of the stakeholder in the whole network as it only considers the local individual network and the direct relationship with an actor and ignores indirect connections with other agents. Betweenness centrality, on the contrary, is more accurate than closeness centrality in relation measurement. Because the closeness centrality will be affected by network connectivity, the accuracy of calculation for nonconnected networks is low. Moreover, people with high betweenness have the potential to control others by controlling and filtering the information flowing between them [53]. Therefore, betweenness centrality is chosen to represent the influence of the stakeholders, with different response strategies for relational risks being obtained according to the two dimensions: ego density and betweenness centrality [7].
Stakeholders can be divided into four types according to their respective ego density and centrality.

5.1.1. Higher Ego Density-Higher Betweenness Centrality. Stakeholders with such network characteristics have a greater ability to control resources (higher betweenness) but are greatly constrained by others and have less autonomy (higher ego density). Mutual checks and balances between stakeholders restrict the resource advantages of stakeholders. At this point, stakeholder decision-making involves some risk because of the behavioral uncertainty of other stakeholders. In order to increase their comparative advantage and maximize resource utilization, such stakeholders need to find ways for reducing their individual network density.

5.1.2. Higher Ego Density-Lower Betweenness Centrality. Stakeholders with these network characteristics have low freedom and weak resource control, with a higher risk of being pinned down by other stakeholders in the network. High density means they achieve common goals, mainly through frequent communication with others. At the same time, lower centrality forces them to rely on external key resource supply organizations. According to resource dependence theory, in order to increase their competitive advantage, they must establish a stable source of external resources. The choice to cooperate with stakeholders with a better ability will greatly improve their chances of obtaining resources and reducing risks.

In view of this kind of stakeholder group, this study suggests that we should cooperate with the appropriate subjects to improve influence in the network and reduce the constraints. In order to investigate whether the main network structure changes before and after cooperation, the matrix and social network model after cooperation are reconstructed, and the revised network indicators are calculated and compared with those before cooperation. The research assumes that the two subjects will share their status advantages after cooperation. For example, if $X_{1 j}$ and $X_{2 j}$ are the impact values of node 1 and node 2 on node $j$, respectively, then the impact values of node 1 and node 2 on node $j$ after cooperation are $X_{12-\mathrm{j}}=\max \left(X_{1 j}, X_{2 j}\right)$.

\subsubsection{Lower Ego Density-Higher Betweenness Centrality.} Stakeholders with such network characteristics have greater independence, have a greater ability to control resources, and are leaders of the whole network. Such organizations have an absolute advantage in the relational network, and their risk mainly comes from project property risk rather than relational risk. This should give full play to their own advantages and maintain the stability and effectiveness of the whole network. In addition, they may be concerned about potential threats to their core position posed by the excessive alignment of other stakeholders in the network.

5.1.4. Lower Ego Density-Lower Betweenness Centrality. Stakeholders with such network characteristics have more freedom, less control over network resources, and less 
contact with other people. Such stakeholders occupy the edge of the network, participate less in the project, and have a correspondingly low risk.

As shown in Figure 2, this case project involves two categories of stakeholders: higher ego density-lower betweenness centrality (located in the lower right corner in Figure 2) and lower ego density-higher betweenness centrality (located in the upper left corner in Figure 2). The construction agent unit and government belong to the latter and are in the dominant position, while other stakeholders belong to the former, in a relatively weak position.

Next, the paper discusses the network characteristics of the four main participants in this project (i.e., the government, construction agent, contractor, and supervisor) and the risk coping strategies involved. As the stakeholders in the lower right corner are in the same position, the nature of the relationship risks they may encounter is similar. Therefore, the constructor and supervisor are selected as representatives.

\subsection{Response by Stakeholder Type}

5.2.1. Government and Construction Agent Unit. The government and the construction agent unit have the highest betweenness centrality (19.815), and their individual network densities are $37.38 \%$ and $35.56 \%$, respectively. Located in a high-centrality and low-density network, their ability to control resources and information is strong and the constraints from other stakeholders are minimal, making them project leaders in the network.

The two sides have a similar status in the network, which means that they will restrict each other. In other words, they are the mutual source of uncertain relationship risk. The administrative function of the government is higher than that of the construction agent, but the project management ability of the agent is higher than that of the government. At the same time, they pursue different interests, where the government pays more attention to the social benefits of the project, while the agent pays more attention to the economic benefits-they interrestrict. The local governments also include customs, immigration, and the National Inspection and Quarantine Bureau, and therefore, the government plays an indispensable role in coordination and monitoring to ensure the smooth progress of the project. On the contrary, the agent is the actual person in charge of the project and has advantages of professional expertise. Their respective advantages can just make up for the shortcomings of both sides; that is, the government uses its own specific rights to coordinate the relationships between departments, while the agent units use their own professional skills to improve project performance. Good communication and coordination between them must be carried out to minimize their risks. Moreover, the two stakeholders are the core actors in this project, being the uncertain risk source of the whole relationship network and having a greater impact on other stakeholders and even the whole network.

5.2.2. Contractor. The contractor has a comparatively high betweenness degree (3.148), ranked third, implying some capacity to control resources and information. Meanwhile, the individual network density ranks third from the end (55.36\%). Thus, its individual network risk is medium. In consideration of the stakeholders who have direct contact with the contractor and have higher resources and information than contractors, the contractor should consider cooperating with the construction agent units to improve their own influence and reduce their governance risks.

Therefore, according to the principle of establishing the cooperation matrix mentioned in Section 5.1, the cooperation matrix of the contractor and the construction agent is constructed, and betweenness centrality and ego density are calculated. The corresponding measurements are shown in Table 4 . The centrality and density are 3.148 and 55.36, respectively, before coordination and 23.333 and 29.17, respectively, after coordination, indicating that the centrality of the contractor is greatly improved after collaboration and the individual network density is reduced. Furthermore, the contractors have higher independence with the increasing status of the network and ability to obtain resources and information. Clearly, after cooperating, the contractor's ability to control the resources has been strengthened, which reduces the risk of an uncertain relationship caused by an excessive dependence on others.

5.2.3. Supervisor. The betweenness centrality of the supervisor is ranked fifth $(0.741)$, indicating that the ability to control resource information is relatively weak, and its ego network density is $69.05 \%$, which means that the supervisor's ego network is larger and more easily influenced and restricted by the other stakeholders. Dependence on others makes them passive. The risk of their relationship stems from the uncertainty of others' behavior. In order to reduce their own risk, they should consider how to reduce their dependence on others, minimize the influence of others on themselves, and improve their autonomy of behavior. According to the questionnaire survey, the contractor and the construction agent have more direct contact with the supervisor, and therefore, supervisors can choose to cooperate with one of them to improve their own centrality and reduce density to improve the status.

According to the principle of establishing the cooperation matrix mentioned in Section 5.1, the cooperation matrix of the supervisor and the construction agent and the cooperation matrix of the supervisor and the contractor are constructed. The corresponding measurements are shown in Table 5. The supervisor, supervisor-contractor, and supervisor-construction agent unit have a value of $0.741,3.426$, and 21.481 , respectively, for betweenness centrality and $69.05,52.38$, and 31.94, respectively, for ego network density, indicating that, clearly, the individual network density of the supervision is greatly reduced and its centrality degree is greatly improved after cooperating with the construction agent unit.

\section{Discussion}

Successful project completion requires the cooperation of all participants, and thus, their overall ability is more important 


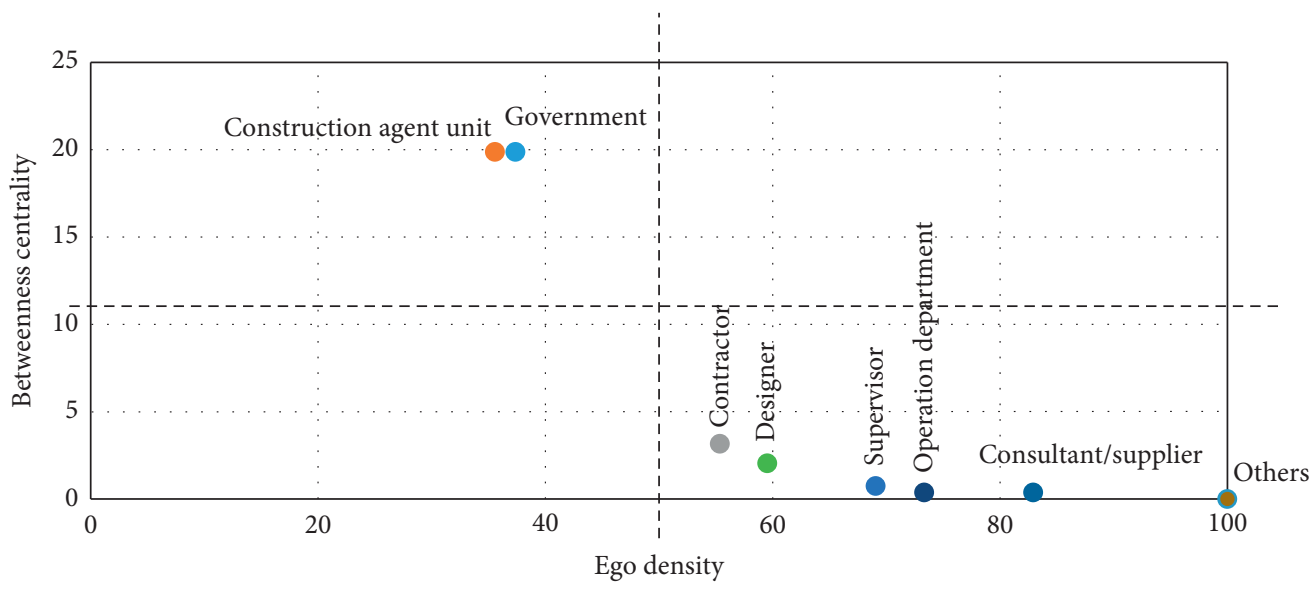

Figure 2: Position of stakeholders.

TABle 4: Comparison of centrality and density between the two modes.

\begin{tabular}{lcc}
\hline Stakeholders & Centrality & Density \\
\hline Contractor & 3.148 & 55.36 \\
Contractor-construction agent & 23.333 & 29.17 \\
\hline
\end{tabular}

TABle 5: Comparison of centrality and density between the three modes.

\begin{tabular}{lcc}
\hline Stakeholders & $\begin{array}{c}\text { Betweenness } \\
\text { centrality }\end{array}$ & $\begin{array}{c}\text { Ego network } \\
\text { density }\end{array}$ \\
\hline Supervisor & 0.741 & 69.05 \\
Supervisor-contractor & 3.426 & 52.38 \\
$\begin{array}{l}\text { Supervisor-construction } \\
\text { agent }\end{array}$ & 21.481 & 31.94 \\
\hline
\end{tabular}

than that of individual participants [54]. When pursuing their own interests, it is important that all stakeholders also share resources and information to promote the completion of the project jointly, as the key to its success lies in the continuous cooperation between stakeholders [55].

Core stakeholders usually control most of the resources and information in the network; they act as the glue that holds the parts of a system together, and weaknesses at these critical points can lead to disintegration [56]. For core stakeholders, their risk comes from property risk rather than relationship risk. However, they are the source of relationship risk for other stakeholders throughout the network. They usually hold the vast majority of resources and information and have greater power. Other stakeholders need to rely on them for more resources and are even restricted by them. Through the above analysis, it is found that the government has an absolute advantage in the project, which is a significant issue in China, where megaprojects usually have considerable government involvement. Thus, many enterprises tend to work closely with local governments and other authorities, as China's media and government agencies mainly control the greatest amount of scarce resources [30]. At a later stage of the research, we returned to the project to further understand its progress and found that parts of the project had been shut down for about six months and the bidding, material procurement, and other works were making slow progress. As a result, the project was one year behind the original schedule, and overall construction cost increased significantly. This was partly due to temporary changes of the organizational structure during the progress of the project, where the responsibilities of the Bridge Office were changed from direct participation in construction to either pure supervision or pure coordination. This resulted in many unclear jobs in terms of power and responsibility, directly affecting the Bridge Office and the construction agent units, while indirectly affecting the related work of the contractor and engineer.

Contractors, designers, supervisors, and others have a relatively weak status in the network compared with the core stakeholders, with a higher ego density and lower betweenness centrality, and therefore, they are more likely to be constrained by other stakeholders, are only weakly autonomous, and have access to only limited resources. Their relationship risk comes from the behavior of others. That is, the realization of their goals may depend on other stakeholders to provide resources; their project interests are affected by key stakeholders. According to resource dependence theory, enterprises should reduce their dependence on external organizations that provide critical resources and try to maintain a stable supply of external key resources. In this case, it is necessary for these stakeholders in the asymmetric relationship network to obtain common resources by cooperating with each other [57]. In particular, establishing joint relationships with key stakeholders in the network can help them control network resources more effectively (such as information, services, and materials), to improve their ability to cope with the pressure of the network structure [37, 58].

Based on the SNA used in this study, it is found that when the stakeholders choose to cooperate with others, their own network status improves, the influence and resource acquisition ability increase, and the relationship risk reduces accordingly. Previous research also indicates that stakeholders will work collaboratively to obtain the necessary resources [59], enhance their position, and modify institutional structures [60]. In this case, the participants (especially the government and construction agent unit) 
became aware of the existing problems after the project was postponed for a year and found an appropriate solution through communication and coordination and started to cooperate with each other to promote the smooth progress of the project.

In addition, there are two points worth noting. Firstly, the risk management measures proposed in the study are mainly based on individual stakeholders, but from the perspective of overall project governance, we need to pay attention to the possible behavior alienation in the process of interagent cooperation. Secondly, the risk prevention measures proposed in this study are not applicable to each subject. For some marginal subjects, such as the financial institution, scientific institution, and public facility management department in this case, they participate in the project for a short time, in a shallow depth, and hardly directly participate in the project construction. Therefore, for them, it is not necessary to improve their position in the network.

\section{Conclusion}

This paper analyzes individual stakeholders in the network of the Zhuhai Port project of the Hong Kong-ZhuhaiMacao Bridge and their mutual influences. It is found that each participant's behavior influences the others, and vice versa, increasing the risks to themselves, the others, and even the whole project. From a sociological point of view, different stakeholders should try to improve their centrality and reduce network density to reduce their risk by increasing their ability to access resources and enhance their influence and independence, mainly through choosing appropriate partners. In addition, the key stakeholders are particularly important, being at the core of the network and with great influence on the network structure and the other participants. They are the therefore the commanders of the network, can control the critical information flow of the whole network, and are a key factor in maintaining the stability and effectiveness of the whole network, making them the main monitoring targets.

The findings provide a number of practical implications and further demonstrate the importance of teamwork. For example, the contractors can improve their position in the project through the establishment of a good partnership with the construction unit. They also can improve their prediction and decision-making abilities with better access to information and resources. Similarly, the supervisor's timely communication and cooperation with the construction agent unit can help improve the acquisition of the overall and carry out more effective supervision.

A limitation is the relatively one-sided concern of relational risk. More comprehensive studies are needed of the relationship risk and attribute risk. Individual attribute risk and network environment risk could be taken into account with the help of network theory while considering the interaction of stakeholders in the network. Moreover, a more comprehensive form of network risk management could be carried out according to the characteristics of two types of risks involved.

\section{Data Availability}

All data generated or used during the study are available from the corresponding author by request.

\section{Conflicts of Interest}

The authors declare that they have no conflicts of interest.

\section{Acknowledgments}

The authors gratefully acknowledge the funding and support provided by the National Natural Science Foundation of China (NSFC) (Grant No. 71871096).

\section{References}

[1] H. Ma, S. Zeng, H. Lin, H. Chen, and J. J. Shi, "The societal governance of megaproject social responsibility," International Journal of Project Management, vol. 35, no. 7, pp. 1365-1377, 2017.

[2] P. K. Gellert and B. D. Lynch, "Mega-projects as displacements," International Social Science Journal, vol. 55, no. 175, pp. 15-25, 2003.

[3] H. Chen, Q. Su, S. Zeng, D. Sun, and J. J. Shi, “Avoiding the innovation island in infrastructure mega-project," Frontiers of Engineering Management, vol. 5, no. 1, pp. 109-124, 2018.

[4] S. Floricel and R. Miller, "Strategizing for anticipated risks and turbulence in large-scale engineering projects," International Journal of Project Management, vol. 19, no. 8, pp. 445-455, 2001.

[5] I. Kardes, A. Ozturk, S. T. Cavusgil, and E. Cavusgil, "Managing global megaprojects: complexity and risk management," International Business Review, vol. 22, no. 6, pp. 905-917, 2013.

[6] S. Bertelsen, "Complexity-A new way of understanding construction," in Proceedings of the 11th Annual Conference of the International Group for Lean Construction, Blacksburg, VA, USA, September 2003.

[7] X. Liu and R. Liu, "Relationship risk analysis in project governance," in Proceedings of the 2014 International Conference on Management Science and Management Innovation, pp. 95-102, Changsha, China, June 2014.

[8] R. Müller, L. Zhai, and A. Wang, "Governance and governmentality in projects: profiles and relationships with success," International Journal of Project Management, vol. 35, no. 3, pp. 378-392, 2017.

[9] M. Pilkienè, R. Alonderienè, A. Chmieliauskas, S. Šimkonis, and R. Müller, "The governance of horizontal leadership in projects," International Journal of Project Management, vol. 36, no. 7, pp. 913-924, 2018.

[10] Z.-J. Wang, R.-H. Zhang, X.-Y. Xie et al., "Field tests and simplified calculation method for static drill rooted nodular pile," Advances in Civil Engineering, vol. 2019, pp. 1-13, 2019.

[11] R. Joslin and R. Müller, "The relationship between project governance and project success," International Journal of Project Management, vol. 34, no. 4, pp. 613-626, 2016.

[12] S. Z. Dogan, D. Arditi, S. Gunhan, and B. Erbasaranoglu, "Assessing coordination performance based on centrality in an E-mail communication network," Journal of Management In Engineering, vol. 31, no. 3, Article ID 4014047, 2013.

[13] B. Peng, X. Gu, Q. Zhou, and B. Wu, "Project governance risk analysis of service-oriented manufacturing based on SNA," Management Review, vol. 28, no. 2, pp. 25-34, 2016. 
[14] L. Yang, "Research on organizing network model for complex construction project based on social network analysis," Engineering Journal of Wuhan University, vol. 45, no. 3, pp. 345-349, 2012.

[15] S.-C. Lin, "An analysis for construction engineering networks," Journal of Construction Engineering and Management, vol. 141, no. 5, Article ID 4014096, 2015.

[16] J. Yuan, K. Chen, W. Li, C. Ji, Z. Wang, and M. J. Skibniewski, "Social network analysis for social risks of construction projects in high-density urban areas in China," Journal of Cleaner Production, vol. 198, pp. 940-961, 2018.

[17] C. Winship, S. Wasserman, and K. Faust, "Social network analysis: methods and applications," Journal of the American Statistical Association, vol. 91, no. 435, p. 1373, 1996.

[18] S. Ferriani, G. Cattani, and C. Baden-Fuller, "The relational antecedents of project-entrepreneurship: network centrality, team composition and project performance," Research Policy, vol. 38, no. 10, pp. 1545-1558, 2009.

[19] P. Chinowsky, J. Diekmann, and V. Galotti, "Social network model of construction," Journal of Construction Engineering and Management, vol. 134, no. 10, pp. 804-812, 2008.

[20] M. Danilovic and T. R. Browning, "Managing complex product development projects with design structure matrices and domain mapping matrices," International Journal of Project Management, vol. 25, no. 3, pp. 300-314, 2007.

[21] C. Lee, H. Chong, P. Liao, and X. Wang, "Critical review of social network analysis applications in complex project management," Journal of Management in Engineering, vol. 34, Article ID 40170612, 2018.

[22] F. U. Pappi and J. Scott, "Social network analysis: a handbook," Contemporary Sociology, vol. 22, no. 1, p. 128, 2000.

[23] M. Winter, C. Smith, P. Morris, and S. Cicmil, "Directions for future research in project management: the main findings of a UK government-funded research network," International Journal of Project Management, vol. 24, no. 8, pp. 638-649, 2006.

[24] S. Badi and D. Diamantidou, "A social network perspective of building information modelling in Greek construction projects," Architectural Engineering and Design Management, vol. 13, no. 6, pp. 406-422, 2017.

[25] M. Cai, W. Wang, Y. Cui, and H. E. Stanley, "Multiplex network analysis of employee performance and employee social relationships," Physica A: Statistical Mechanics and Its Applications, vol. 490, pp. 1-12, 2018.

[26] B. Pauget and A. Wald, "Relational competence in complex temporary organizations: the case of a French hospital construction project network," International Journal of Project Management, vol. 31, no. 2, pp. 200-211, 2013.

[27] F. Y. Y. Ling, S. Y. Ong, Y. Ke, S. Wang, and P. Zou, "Drivers and barriers to adopting relational contracting practices in public projects: comparative study of Beijing and Sydney," International Journal of Project Management, vol. 32, no. 2, pp. 275-285, 2014.

[28] M. Loosemore, "Social network analysis: using a quantitative tool within an interpretative context to explore the management of construction crises," Engineering Construction and Architectural Management, vol. 5, no. 4, pp. 315-326, 1998.

[29] L. Hossain, "Communications and coordination in construction projects," Construction Management and Economics, vol. 27, no. 1, pp. 25-39, 2009.

[30] R. Ding and F. Liu, "A social network theory of stakeholders in China's project governance," iBusiness, vol. 3, no. 2, pp. 114-122, 2011.
[31] G. Soda, A. Usai, and A. Zaheer, "Network memory: the influence of past and current networks on performance," Academy of Management Journal, vol. 47, no. 6, pp. 893-906, 2004.

[32] S. D. Pryke, "Legal issues associated with emergent actor roles in innovative U.K. Procurement: prime contracting case study," Journal of Professional Issues in Engineering Education and Practice, vol. 132, no. 1, pp. 67-76, 2006.

[33] L. Yongkui, L. Yujie, H. K. Young, L. Yun, and H. Qinghua, "Social network analysis and organizational control in complex projects: construction of EXPO 2010 in China," Engineering Project Organization Journal, vol. 1, no. 4, pp. 223-237, 2011.

[34] J. E. Taylor, P. G. Bernstein, and G. Phillip, "Paradigm trajectories of building information modeling practice in project networks," Journal of Management In Engineering, vol. 25, no. 2, pp. 69-76, 2009.

[35] J. L. Nelon, W. Garney, E. Aparicio et al., "225. Utilization of social network analysis to understand relationships in program measures for youth who experience homelessness," Journal of Adolescent Health, vol. 64, no. 2, p. S115, 2019.

[36] S. Badi, L. Wang, and S. Pryke, "Relationship marketing in Guanxi networks: a social network analysis study of Chinese construction small and medium-sized enterprises," Industrial Marketing Management, vol. 60, pp. 204-218, 2017.

[37] F. Liu, Research on the Dynamic Governance Relationships Among Project Stakeholders, Shandong University, Jinan, China, 2012.

[38] M. Loosemore, "Responsibility, power and construction conflict," Construction Management and Economics, vol. 17, no. 6, pp. 699-709, 1999.

[39] K. Aaltonen, K. Jaakko, and O. Tuomas, "Stakeholder salience in global projects," International Journal of Project Management, vol. 26, no. 5, pp. 509-516, 2008.

[40] C. Yuan, "Research on risk management organization of subway construction project based on social network analysis," in Advances in Social Science Education and Humanities Research, L. Liu, G. Ke, and H. Davis, Eds., vol. 151, pp. 464-468, 2018.

[41] H. Lingard, P. Pirzadeh, N. Blismas, R. Wakefield, and B. Kleiner, "Exploring the link between early constructor involvement in project decision-making and the efficacy of health and safety risk control," Construction Management and Economics, vol. 32, no. 9, pp. 918-931, 2014.

[42] R. Ding, S. Gao, L. Wang, and T. Sun, "Network dynamic analysis based risk management for collaborative innovation projects," in Proceedings of the 2017 12th International Scientific and Technical Conference on Computer Sciences and Information Technologies (CSIT), Lviv, Ukraine, September 2017.

[43] R. J. Yang, P. X. W. Zou, and J. Wang, "Modelling stakeholder-associated risk networks in green building projects," International Journal of Project Management, vol. 34, no. 1, pp. 66-81, 2016.

[44] R.-X. Ding, X. Wang, K. Shang, and F. Herrera, "Social network analysis-based conflict relationship investigation and conflict degree-based consensus reaching process for large scale decision making using sparse representation," Information Fusion, vol. 50, pp. 251-272, 2019.

[45] D. Dang-Pham, S. Pittayachawan, V. Bruno, and K. Kautz, "Investigating the diffusion of IT consumerization in the workplace: a case study using social network analysis," Information Systems Frontiers, vol. 21, no. 4, pp. 941-955, 2019. 
[46] L. A. Goodman, "Snowball sampling," The Annals of Mathematical Statistics, vol. 32, no. 1, pp. 148-170, 1961.

[47] N. Garcia and R. G. Eccles, "Networks and organizations: structure, form, and action," IEEE Transactions on Systems Man and Cybernetics Part C Applications and Reviews, vol. 28, no. 2, pp. 173-193, 1992.

[48] J. Scott, Social Capital: A Theory of Social Structure and Action (Review), Cambridge University Press, Cambridge, UK, 2001.

[49] K. S. Cook, "Exchange and power in networks of interorganizational relations," The Sociological Quarterly, vol. 18 , no. 1 , pp. $62-82,1977$.

[50] R. M. Emerson, "Power-dependence relations," American Sociological Review, vol. 27, no. 1, pp. 31-41, 1962.

[51] O. C. E. O. Fdad, Models and Methods in Social Network Analysis, Cambridge University Press, Cambridge, UK, 2012.

[52] S. D. Pryke, "Analysing construction project coalitions: exploring the application of social network analysis," Construction Management and Economics, vol. 22, no. 8, pp. 787-797, 2004.

[53] L. C. Freeman, "Centrality in social networks conceptual clarification," Social Networks, vol. 1, no. 3, pp. 215-239, 1978.

[54] I. Ruuska, T. Ahola, M. Martinsuo, and T. Westerholm, "Supplier capabilities in large shipbuilding projects," International Journal of Project Management, vol. 31, no. 4, pp. 542-553, 2013.

[55] S. Lee and G.-W. Choi, "Governance in a river restoration project in South Korea: the case of incheon," Water Resources Management, vol. 26, no. 5, pp. 1165-1182, 2012.

[56] B. S. Cohn and M. Marriott, "Networks and centres of integration in Indian civilization," Journal of Social Research, vol. 1, no. 1, pp. 1-9, 1958.

[57] B. Wellman, "Network analysis: some basic principles," Sociological Theory, vol. 1, no. 1, pp. 155-200, 1983.

[58] A. Kolk and J. Pinkse, "Stakeholder mismanagement and corporate social responsibility crises," European Management Journal, vol. 24, no. 1, pp. 59-72, 2006.

[59] X. Tong and H. T. Peng, "Factors and propensity score analysis for social network evolution of business cor-porations," Enterprise Reform and Development, vol. 5, pp. 164$166,2010$.

[60] C. W. L. Hill and T. M. Jones, "Stakeholder-agency theory," Journal of Management Studies, vol. 29, no. 2, pp. 131-154, 1992. 


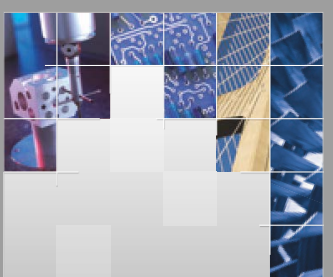

\section{Enfincering}
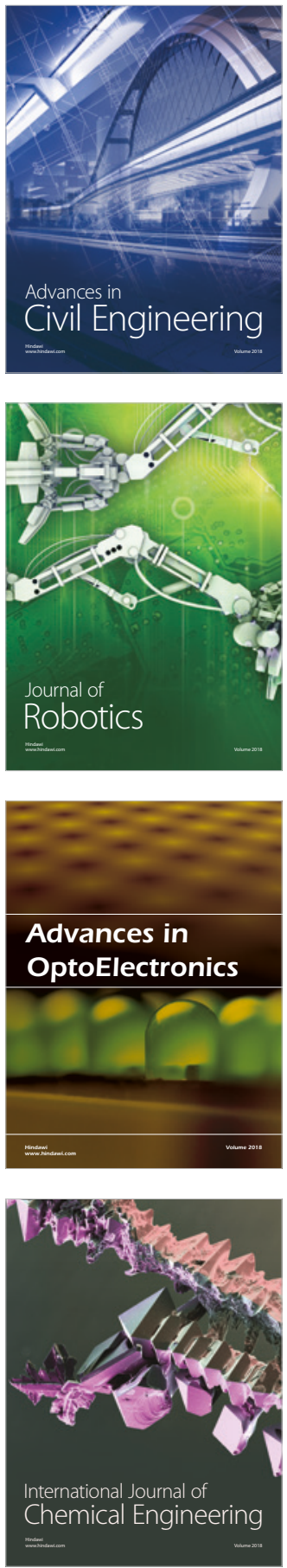

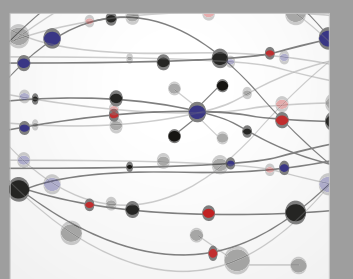

\section{Rotating \\ Machinery}

The Scientific World Journal

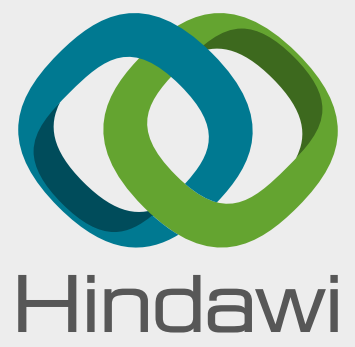

Submit your manuscripts at

www.hindawi.com
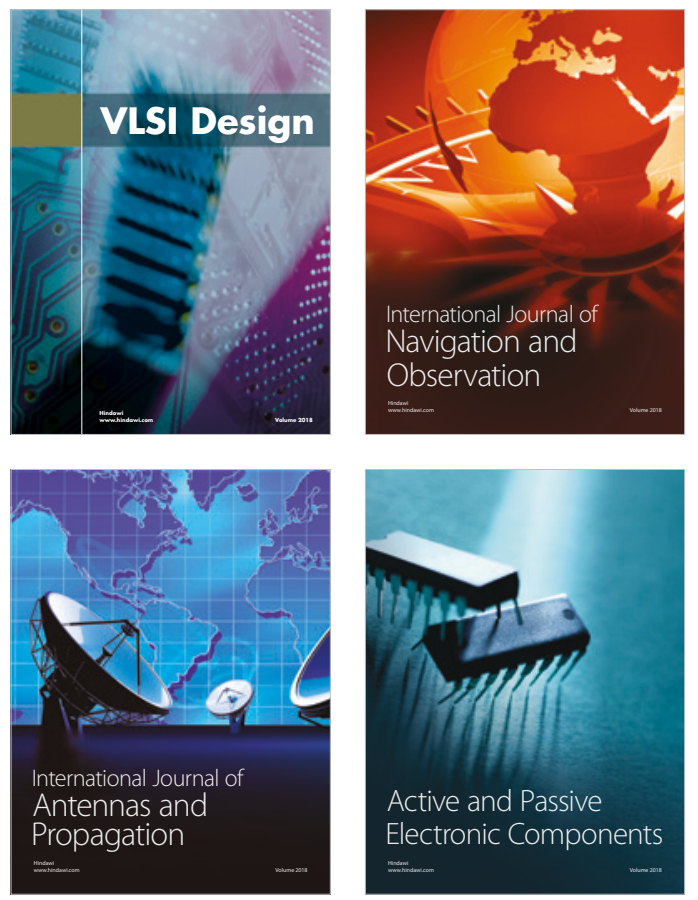
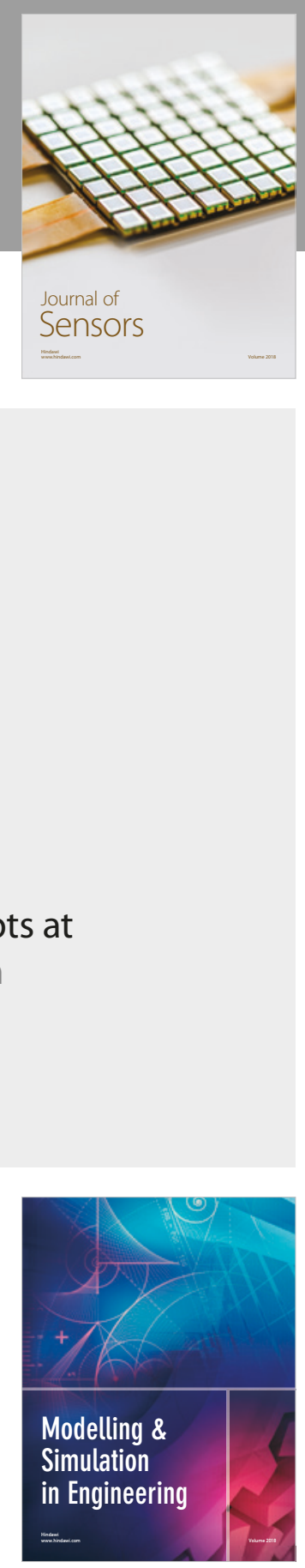

\section{Advances \\ Multimedia}
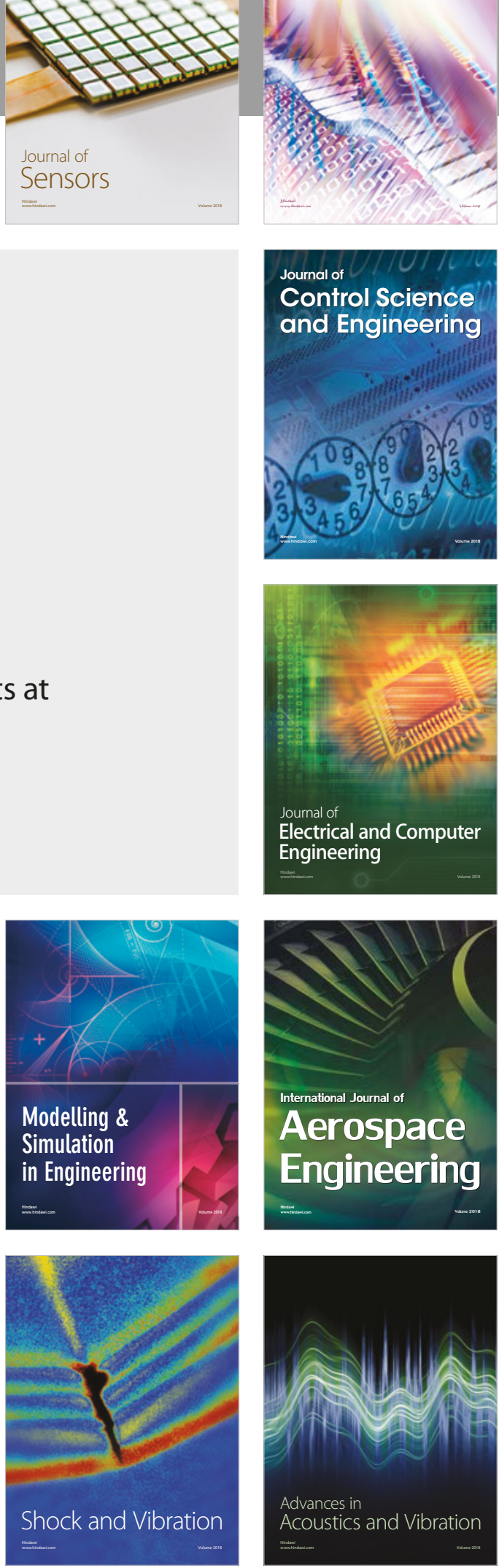